\title{
AN ANEROID CALORIMETER FOR SPECIFIC AND LATENT HEATS
}

\author{
By Nathan S. Osborne
}

\section{CONTENTS}

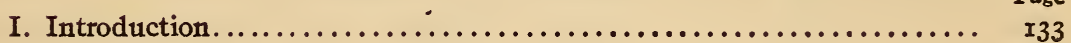

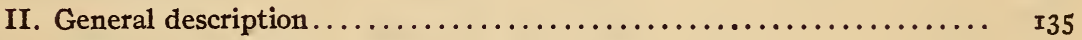

III. Detailed description. ................................... I36

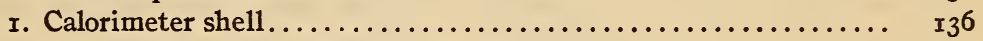

2. Heating element........................... I39

3. Calorimeter thermometer........................... I40

4. Jacket. ................................. I40

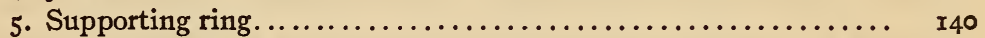

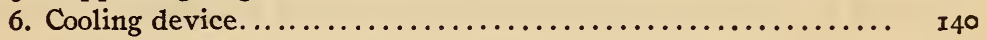

7. Electric leads................................. I4I

8. Connections to interior........................... I42

9. Integrating thermocouples......................... I43

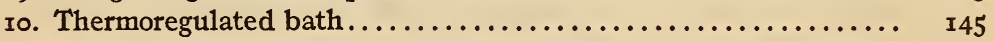

IV. Accessories..................................... I46

r. Condenser................................... I46

2. Manometer..................................... I46

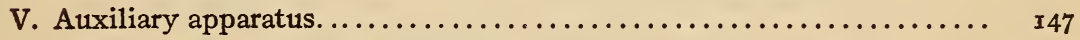

I. Wheatstone bridge............................. I47

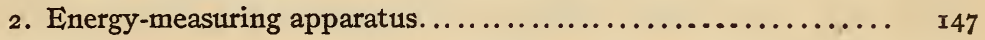

VI. Calibration....................................... I47

I. Calibration of resistance thermometer.................. I47

2. Rate of thermal leakage......................... I48

3. Thermocouple calibration. ....................... I49

4. Heat-capacity determinations......................... I5

5. Experimental results................................. I5I

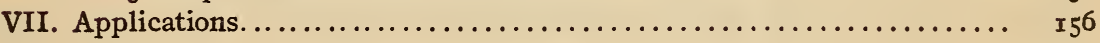

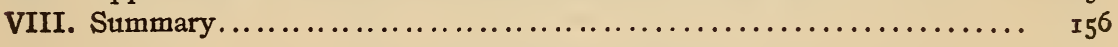

\section{INTRODUCTION}

The calorimeter here described has been designed primarily for the measurement of the specific heats and the latent heats of a certain class of materials adapted for use in the production of artificial refrigeration. These materials include ammonia, carbon dioxide, sulphur dioxide, methyl chloride, and ethyl chloride. At temperatures where the thermal properties are of importance to the engineer the vapor pressures of these materials range from less than I atmosphere to over 70 atmospheres. 
Calorimetric measurements upon such active substances require special provision for mechanical isolation in addition to the means for measuring the heat-absorbing ability, because these thermal properties are indefinite unless the substance is kept under control as regards pressure and volume. The instrument must accomplish the thermal isolation of a system composed of the material, its container, and special parts for measuring quantities of heat exchanged, as well as the mechanical isolation and control of the material.

The principle of the unstirred or "aneroid" type of calorimeter, as developed by Eücken, ${ }^{1}$ Nernst, ${ }^{2}$ and associates, Harper, ${ }^{3}$ Dickinson, ${ }^{4}$ and others, utilizing instead of the convection of a stirred liquid the conduction of the parts for distributing heat developed electrically, offers an elegant means of fulfilling these requirements. A calorimeter of this type, which has been previously described, ${ }^{4}$ was used to measure the specific heat and latent heat of ice, and subsequently after being modified so as to adapt it to the material, it was used to determine the specific heat and heat of vaporization of ammonia.

While the results of these latter experiments would perhaps have met the immediate needs of the engineering profession, they did not promise to yield final values which would bear strictest scientific scrutiny, owing to certain instrumental characteristics which, though causing no difficulty in the experiments with ice, yet under the new conditions interfered with efficient completion of the intended experimental program and so left doubt as to the actual order of accuracy attained. In order to dispel all such doubt and establish values of these two important properties which should be authoritative, it was decided to construct another calorimeter embodying as a result of the experience gained, certain new features calculated to add to the convenience of operation, precision of measurement, and facility in executing an adequate experimental program.

The features in which the newly designed calorimeter was expected to excel its predecessor, briefly enumerated, are as follows:

I. Hermetically sealed calorimeter jacket to prevent ingress of the liquid of the thermostat bath. Long continued operation of the aforementioned aneroid calorimeter at widely varied tempera-

\footnotetext{
1 Eücken, Physikalische Zeitschrift, 10, p. 586; 1909.

2 Nernst, Koref, and Lindemann, Sitzungsberichte der Königlich Preussischen Akademie der Wissenschaften, D. 247; 19 ro.

' Harper, Physical Review (2), 1, p. 469; r9r3.

- Dickinson and Osborne, this Bulletin, 12, p. 23; 1915.
} 
tures $\left(-40^{\circ}\right.$ to $\left.+40^{\circ} \mathrm{C}\right)$ invariably developed leaks in the submerged joint where the jacket was closed.

2. Location of the heating coil in the interior portion of the instrument instead of in the outer wall, thereby avoiding so extreme temperature gradients in the surface and favoring the control of thermal leakage.

3. Installation in the calorimeter of a strain-free type of platinum resistance thermometer. The performance of the built-in thermometer of the older calorimeter was unsatisfactory as to precision, it having hysteretic characteristics attributable to mechanical strain.

4. Provision of a mechanically operated device for cooling the calorimeter without introducing variability in its heat capacity.

5. Vertical instead of horizontal arrangement of heat-distributing vanes in the interior calorimetric space to promote uniformity in rate of evaporation. This arrangement was supplemented by a series of baffle plates in the upper part to insure dryness of the vapor.

6. Distribution of connections between calorimeter and jacket so as to render the lead conduction independent either of influences external to the jacket or of the nature of the temperature distribution within the calorimeter.

The instrument has been constructed and determinations have been made of the specific heat, heat of evaporation as well as the latent heat of compression of liquid ammonia. It is expected that similar measurements will be made on other refrigerating media in the near future.

\section{GENERAL DESCRIPTION}

The method by which the calorimeter was to be used is similar to that described in the previous work on the specific and latent heats ${ }^{5}$ of ice.

The material to be investigated is inclosed in a calorimeter of known heat capacity and a measured amount of energy supplied electrically. The initial and final temperatures being measured and the experiment being performed with minimum thermal leakage by the method of keeping the envelope at approximately the same temperature as the calorimeter surface, the data for specific heat of the material are obtained; or, the initial mass in the calorimeter and the amount of vapor removed without changing the temperature being determined, the data are obtained for heat of vaporization. 
A cylindrical metal shell of sufficient strength to withstand the vapor pressure of the material in the temperature range to be covered, provided with an electric heating coil and platinum resistance thermometer located in the central axis, is suspended axially within a metal jacket which is immersed in a thermally controlled liquid bath. An air space between the polished nickel surfaces of calorimeter and jacket furnishes thermal insulation. Two tubes extend from the top of the calorimeter through the jacket and liquid to the outside air, terminating in valves with unions. One of these tubes is intended for connection to pressureindicating apparatus and the other for the introduction and removal of the material to be investigated.

By avoiding heavy metal connections across the air space and by suitably distributing upon the calorimeter surface those connections which are necessary, the part of the thermal leakage due to lead conduction is not only minimized, but also rendered less dependent upon disturbances of thermal equilibrium during experiments than would be the case if the connections were grouped indiscriminately. Thermoelements indicate relative surface temperatures of jacket and calorimeter, ro junctions being distributed upon each surface. This permits close control of thermal leakage and correction for such as it not avoided.

Thermojunctions placed upon the connecting tubes indicate the temperature of these tubes at several points relative to a point on the jacket, for the purpose of ascertaining the temperature of the vapor expelled during vaporization experiments. ${ }^{\circ}$

\section{DETAILED DESCRIPTION}

\section{CALORIMETER SHELL}

The construction of the calorimeter may be seen by reference to the illustrations. Fig. I shows a section through the calorimeter and envelope, Fig. 2 the appearance of the principal parts before assembling, Fig. 3 the same parts partially assembled, while in Fig. 4 the assembled calorimeter is shown ready to be incased in the envelope.

The foundation of this shell consists of steel parts, united by threaded joints put together with tin.

The inside of the central tube is accessible at the bottom for the introduction of the heating coil and thermometer. Upon

\footnotetext{
- The detailed description which immediately follows, up to page 146 , is devoted to a more minute description of the construction, and unless eager for such intimate knowledge, the reader may use his own discretion in omitting the text.
} 


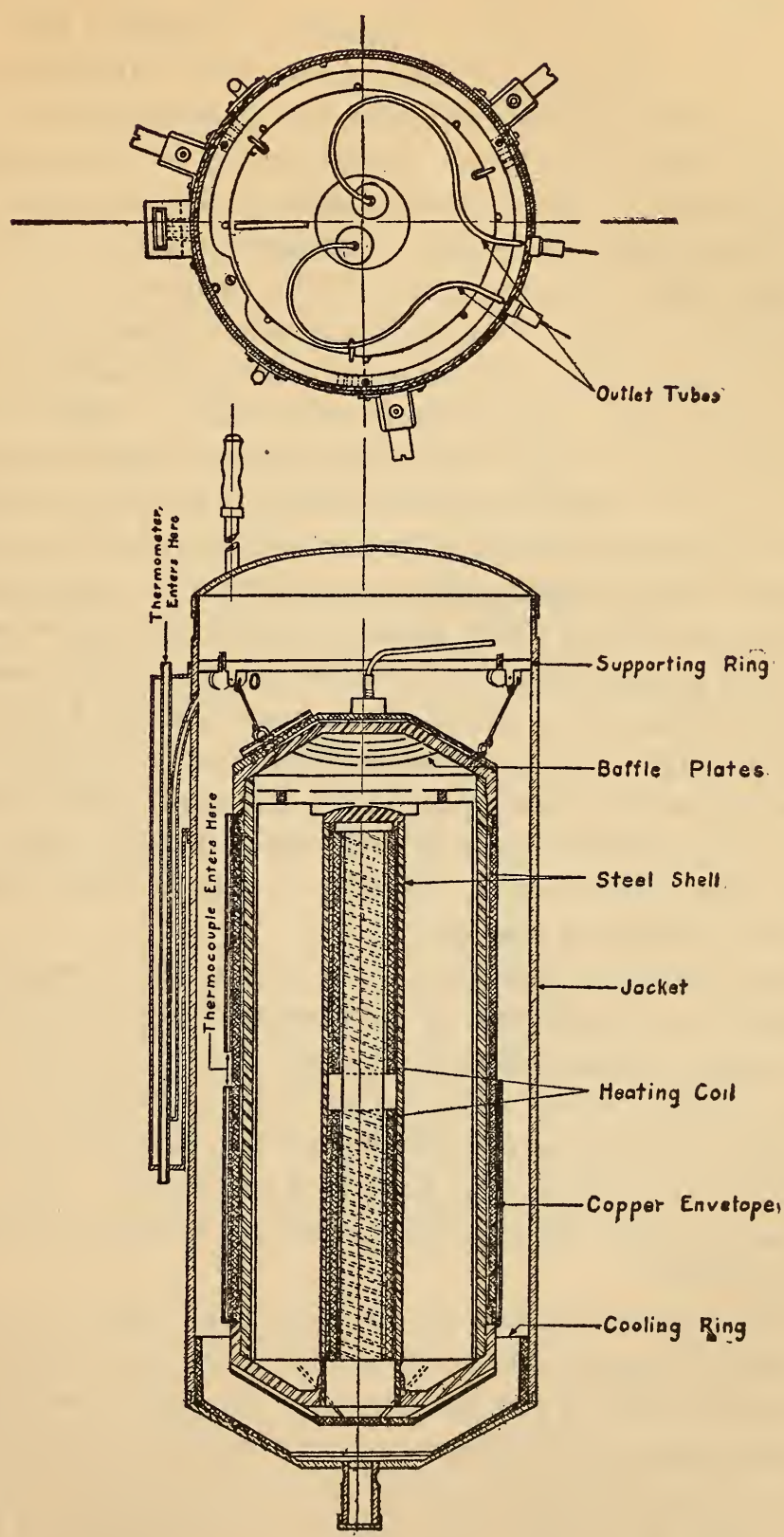

FIG. I.-Sectional view of calorimeter and jacket. ( $1 / 3$ size) 
the outside of this tube, fastened in vertical slots with tin, are I 2 radial vanes of tinned iron about $0.3 \mathrm{~mm}$ thick, extending to within about I $\mathrm{mm}$ of the surrounding cylindrical wall. These vanes are for the purpose of promoting the distribution of heat within the annular space containing the material under investigation. The vanes extend just above the top of the central tube. At this place are two flat circular baffle plates, separated about 2 $\mathrm{mm}$ by three small steel studs. The lower plate is united to the tops of the radial vanes with tin. The clearance to the outside wall is about $0.5 \mathrm{~mm}$. A central hole in the lower plate and several holes in the upper one between center and outside furnish a tortuous passage for vapor coming from below. These two plates are intended to intercept any large drops of liquid which might be thrown up by vigorous boiling, should it occur, and also act as a thermal shield for the top of the calorimeter, for the prevention of excessive local heating either by radiation or convection.

A second set of four baffle plates of spherical contour separated about $2 \mathrm{~mm}$ are attached to the inside surface of the conical part of the calorimeter top. Each plate has a central hole and four slots at the edge so as to avoid trapping gas or liquid, but these passages are so sized and spaced that the main path through the plates is very tortuous, so as to make difficult the passage of liquid particles from below in a current of vapor being withdrawn through the outlets in the top.

In using the older calorimeter for evaporation experiments it was found that the system of horizontal plates installed for the double purpose of heat distribution and drying the vapor did not permit a uniform rate of evaporation to be maintained on account of the sudden increase of evaporating surface when one of the plates emerged from the descending surface of the liquid. The combination of vertical heat distributing plates and system of baffle plates avoids this fault.

The entire inner surface of the steel shell and of the various plates within were all tinned, using pure block tin. Much care and time were devoted to this process with the object of making the tin coating perfect, but the best result obtained still showed a few minute rust spots when the parts were immersed in water. It is possible that these spots were due to fine particles of the steel imbedded in the tin and not to actual holes through the tin coating.

A cylindrical shell of copper about $2 \mathrm{~mm}$ thick envelopes the steel shell between the shoulders formed by the steel end caps. 


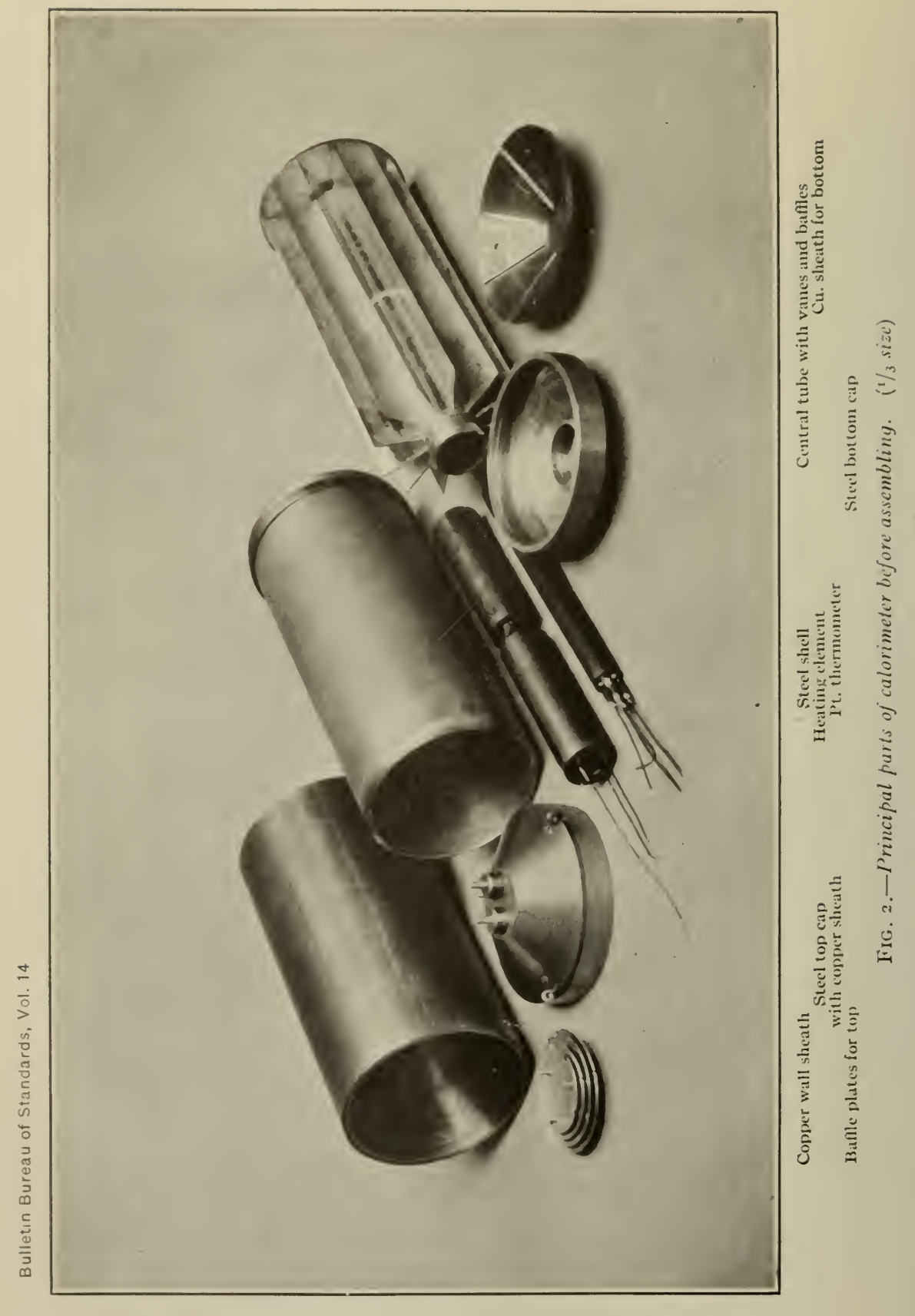




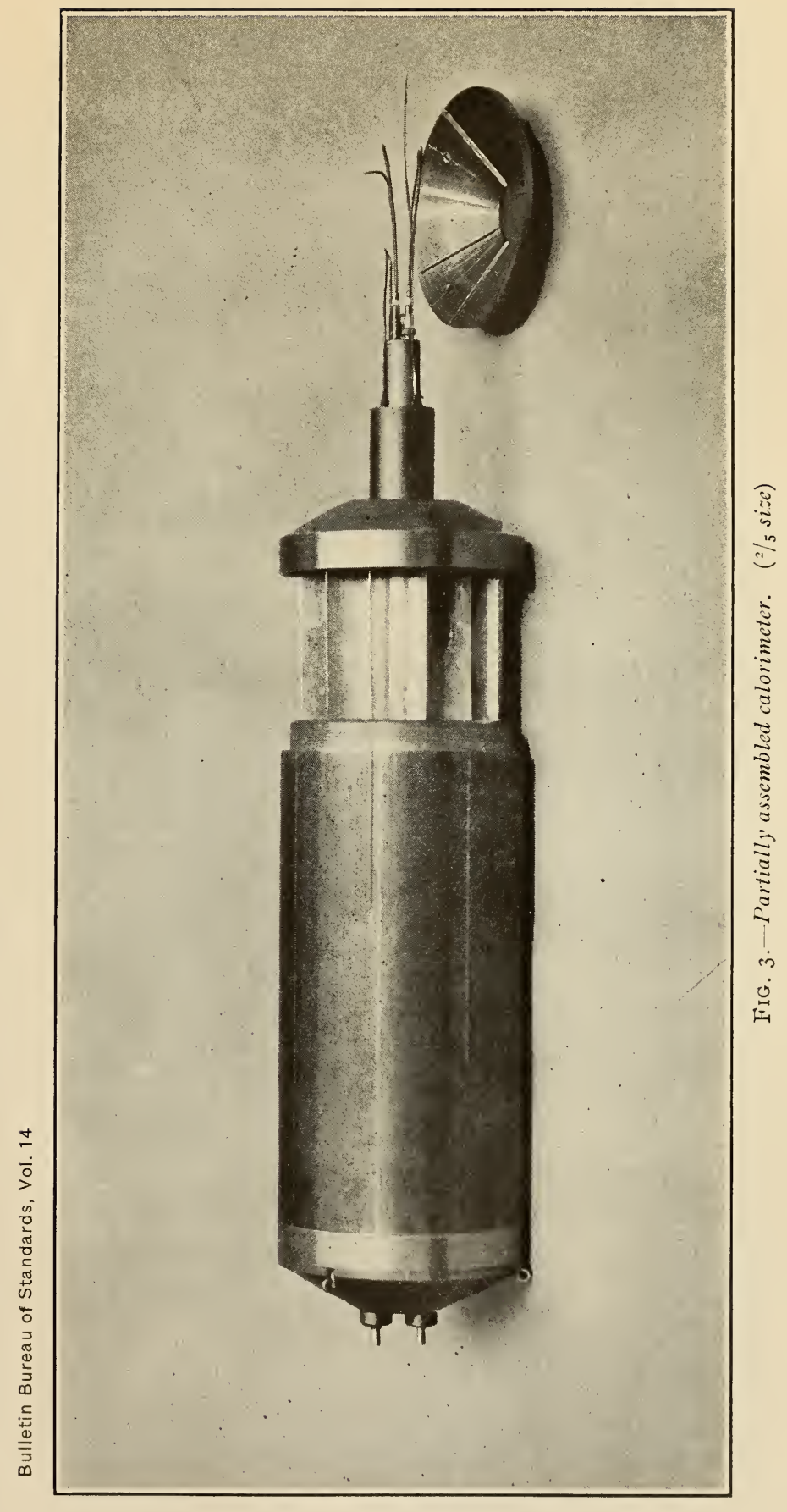


The copper is separated from the steel by an air space of about $0.5 \mathrm{~mm}$ except for a narrow zone at either end where it is united to the steel shell by tin. Conical copper caps likewise envelop the ends, being held in place by screws. The upper cap is separated from the steel top by an air space except at the outer edge. The lower one fits the entire conical surface except for eight slots to accommodate electrical leads. The central space between the lower cap and the shell is large enough to permit electrical connections to be made. The purpose of these copper envelopes about the steel shell is to diminish irregularities in the distribution of the surface temperature such as result from localized heat exchanges inside the shell during experiments. It is apparent that the less abrupt the temperature variation upon the surface, the more perfectly can the surface temperature be ascertained with a given number of thermojunctions.

Three rings attached to the top steel cap and passing through slots in the edge of the copper cap provide for the suspension of the calorimeter in its envelope by fine steel wires.

The vertical ducts through which the electric conductors pass in leading from the heater and thermometer to the points where they leave the calorimeter surface consist of small copper tubes fastened with tin upon the surface of the copper sheath. A similar vertical tube is cut away for a length of $\mathrm{I} \mathrm{cm}$ at the middle to admit the two branches of the integrating multiple thermocouple described elsewhere. A tube soldered on the top and a slot in the lower cap are provided for the two end junctions of the multiple thermocouple. (See Fig. 3.)

\section{HEATING ELEMENT}

The heating element consists of two parts mounted on a common support, each containing a 5 -ohm noninductive resistance of insulated constantan wire so embedded in a copper cylinder as to promote the transfer of heat to the calorimeter. A distance of $\mathrm{I} \mathrm{cm}$ between the inner ends of the mounted coils permits the heat developed to be transmitted either to the upper or lower part of the calorimeter by using the coils independently. By joining two of the terminals only three current leads to the outside are required.

The complete heating element fits closely into the central tube of the calorimeter, and is held in place by a small brass clip fastened to the steel bottom cap. The center of the heater forms a receptacle for the platinum resistance thermometer which is next described. 


\section{CALORIMETER THERMOMETER}

The thermometer, Fig. 2, consists of a coil of the strain-free type previously described by Waidner and Burgess. ${ }^{7}$ The coil of Heraeus highest purity platinum wire o. $\mathrm{rmm}$ in diameter is about $8 \mathrm{~cm}$ long and $7 \mathrm{~mm}$ in diameter. The mica frame supporting this coil fits inside a thin brass tube. The thermometer is of the four-lead potential terminal type, the four copper leads being brought out through porcelain tubes fixed in a plug which is threaded into the brass containing tube. The entire thermometer coil is readily removable from its case and the incased thermometer fits as a unit into its receptacle in the center of the calorimeter.

\section{JACKET}

The jacket consists of a brass cylinder fitted with end caps to close top and bottom when soldered in place. The surfaces are nickel-plated and the interior is polished. It is shown in section in Fig. $I$ and exterior view in Figs. 4 and 5 .

\section{SUPPORTING RING}

The supporting ring for the calorimeter, Fig. 4, furnishes a means of handling the calorimeter with its various attached parts as a unit for assembling in the jacket. The ring slides closely into the jacket resting on three adjustable supports. The calorimeter is suspended from this ring by links of steel piano wire $0.25 \mathrm{~mm}$ in diameter and $2 \mathrm{~cm}$ long. A metal strip fastened to the ring extends downward in close contact with the surface of the jacket, being held in place by four guides. Attached longitudinally to this strip are seven copper tubular ducts for the electric leads. The object of these ducts is to bring the leads to the temperature of the jacket, thus minimizing the influence upon the thermal leakage, of the difference in temperature between the calorimeter and the room. By this device heat conducted by the leads from without the envelope is shunted to the jacket instead of reaching the calorimeter.

\section{COOLING DEVICE}

In use of a previous instrument of somewhat similar construction much time was consumed in cooling the calorimeter by thermal leakage across the insulating air space. The experiment was tried of fitting a small carbon dioxide refrigerating coil to the calorimeter, making connections to the outside by means of small 
Bulletin Bureau of Standards, Vol. 14

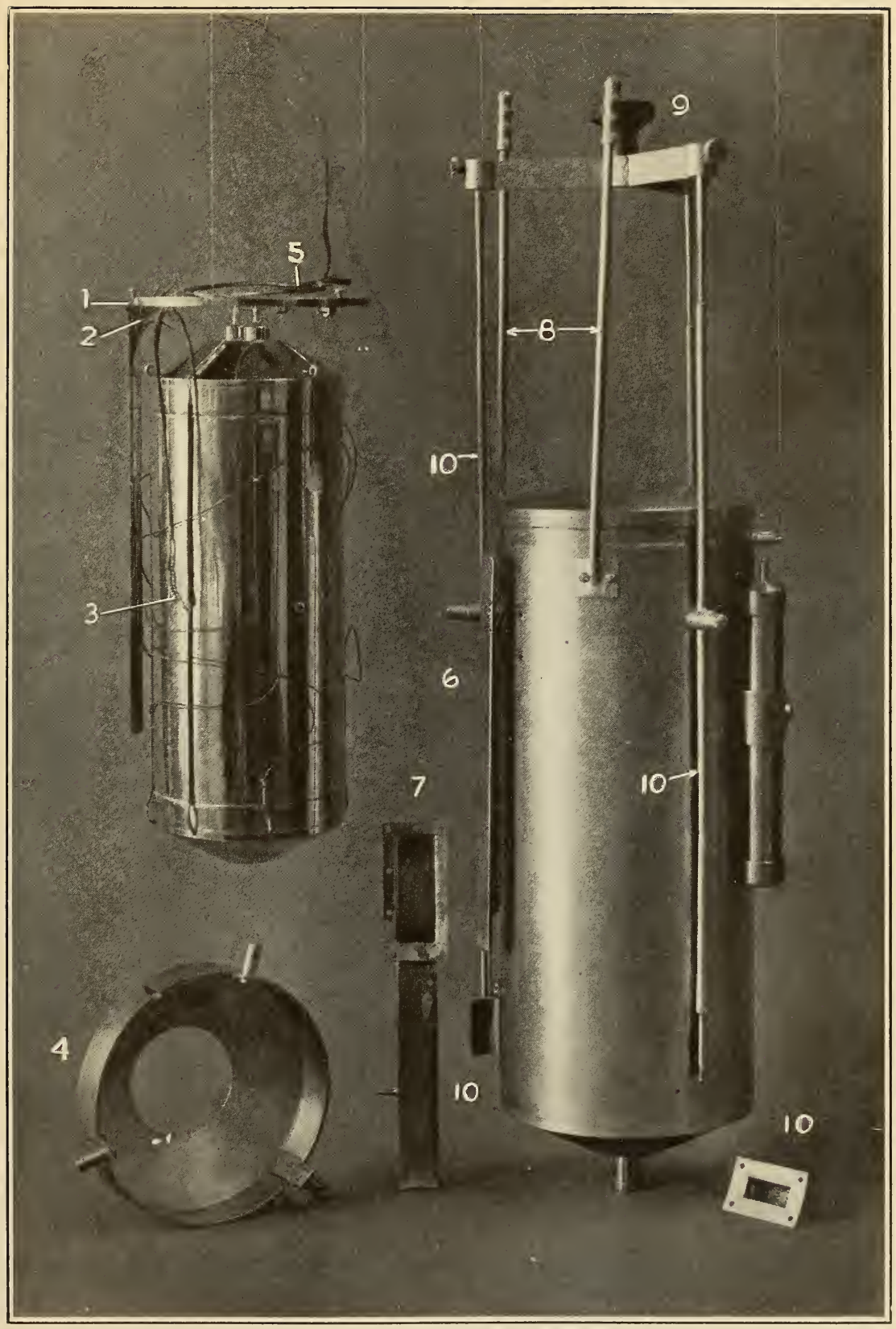

I. Supporting ring

2. Elcetric lead

3. Integrating thermocouples

4. Cooling ring
5. Outflow tubes with thermocouples

6. Receptacle for $t$ c junction and auxiliary thermometer 7. Casing for receptacle
8. Conduits for electric leads

9. Lifter for cooling ring

I0. Casing for ring lifter

FIG. 4.-Calorimeter, cooling ring, and partly assembled jacket. ( $1 / 3$ size) 
thin tubes of low conductivity. This coil was a success in respect to satisfactory refrigeration, but seemed to reduce the calorimetric precision.

The cooling device for the present instrument consists of a copper ring (Fig. 4) having a cylindrical surface shaped to the inside of the jacket and a conical surface shaped to the calorimeter bottom, which can be raised to make contact with both calorimeter and jacket making a thermal short circuit of the insulation to permit rapid thermal leakage or lowered to the bottom of the jacket, leaving the calorimeter thermally insulated. The mechanism for moving the ring consists of three rods extending vertically through tubes to the top of the lagging outside the bath, where they enter a branched handle. The apertures at the top are protected from ingress of water vapor by telescoping joints. At the bottom the rods are threaded into lugs, which extend outward from the ring through slots in the jacket into the casings provided for this connection.

The operation of this device to cool the calorimeter consists in raising the ring into contact with the calorimeter bottom, then reducing the temperature of the jacket and when the calorimeter temperature has fallen sufficiently dropping the ring to the bottom of the jacket of which it then forms a part.

The arrangement has proven satisfactory in every way. The possibility of trouble from condensation of water from the atmosphere in the telescope joints of the lifting rods when operating at low temperatures was anticipated, but it was found that except in very humid conditions these joints remained above the dew point, and that the condensation of water within the tubes could always be avoided by maintaining a very slow stream of dry air entering the jacket through the two electric lead conduits and departing through the three lifter tubes.

\section{ELECTRIC LEADS}

Two tubular metal conduits bring the electric lead wires from within the jacket through the bath to the outside, the thermocouple leads passing through one and the thermometer and heating coil leads through the other. Outside the envelope each set of wires passes through a flexible rubber tube to a glass $T$, in which it is sealed with cement, leaving an air passage into the jacket through each conduit past the wires. Inside the jacket the ends of the conductors are spread out to permit soldered connections to be made with the leads from the calorimeter. The four ther- 
mometer and three heater current leads extend downward through the tubes on the strip attached to the supporting ring (previously described) to the points where they leave the jacket to cross the air space. The conductors crossing this space are made of such a length as to permit a thermally symmetrical distribution of contacts with the calorimeter (see p. 136), keeping the conductors midway of the air space (Fig. 4). The potential leads of the heating coils join the current leads halfway between the points of contact of the current leads with the calorimeter and jacket.

On account of the failure in the heater of insulation which had been tested only at low voltage in the initial assembling of the calorimeter, all the connections to the thermometer and heater were, after repairs, required to show insulation resistance of several thousand megohms when tested at 500 volts. Sufficiently good insulation to withstand this test where the wires pass through the close-fitting copper tubes on the surfaces was obtained by wrapping the wires with several layers of thin, tough, shellaccoated paper well baked in place.

\section{CONNECTIONS TO INTERIOR}

Two tubes are provided for access to the interior of the calorimeter, one for filling or emptying and the other for connecting with a manometer.

It would have been advantageous to have located the valves in these connections at the boundary wall of the calorimeter, but this would have involved rather serious mechanical difficulties. Instead the tubes extend through the envelope to a point outside the lagging, where they terminate in accessible valves. This construction necessitates special precautions to avoid errors due to condensation of vapor or accumulation of liquid within the tubes.

The tubes where they cross the air space between the calorimeter and jacket are of steel O.I mm thick, I.2 mm inside diameter, and Io $\mathrm{cm}$ long, tin coated inside and out. They are made light in order that they may quickly acquire the temperature of vapor flowing out and also to avoid too great thermal conduction. The tubes are symmetrical and slope so as to drain toward the calorimeter.

The temperature of the outflow tube was found to be influenced by the thermocouple leads from without the jacket, owing to their nearness in the air space. The central portion of this tube was observed to be either warmer or cooler than the adjacent ends, depending on whether the thermocouple leads were heated or 
cooled by conduction from the room. When this tube was thus cooled below the saturation temperature of the free surface in the calorimeter, which occurred only when the calorimeter was above room temperature, condensation would occur unless the tube were already full of liquid. This peculiarity was discovered after the determinations of the specific heat at saturation conditions were completed, and its effect is considered in discussing those results. A method of eliminating error from this cause was found and applied in the determinations of latent heat of vaporization. A heating coil placed on the thermocouple-lead conduit outside the bath enabled the temperature of the leads within the jacket to be kept either at or above the calorimeter temperature. Any liquid in the tube could thus be expelled before the beginning of an experiment and its withdrawal unevaporated be thus avoided.

The thermocouples for indicating the temperature conditions of the fluid in the tubes are seven in number, with a common reference junction, the branches being made of equal resistance. To minimize the lag, small (0.1 $27 \mathrm{~mm}$ diameter; B. \& S. gage No. 36) silk and shellac-covered copper and constantan wire were used, the junctions being hard soldered. One junction was placed on the center of the calorimeter top and three on each tube at points dividing the length into four equal parts. For electrical insulation the tubes were first wrapped with a thin layer of shellacked silk fiber at the places where the bare junctions were to be put, and then, to insure good thermal contact, the thermocouple wires laid longitudinally were bound in place with silk fiber and shellacked. The reference junction when in place is in good thermal contact with the jacket near the outflow tube.

Beyond the jacket, tubes are used of smaller internal diameter (about $0.6 \mathrm{~mm}$ ). To allow these tubes to be kept at a temperature above that of the liquid bath through which they pass, a heating element is bound longitudinally on each and the whole sheathed with a copper tube, leaving a small air space. A thermoelement placed on each tube indicates the rise in temperature above the bath.

\section{INTEGRATING THERMOCOUPLES}

To provide for the indication of the relative surface temperatures of calorimeter and jacket at any instant, two integrating multiple thermocouples are employed. Each of these when used alone indicates the mean temperature of one of the surfaces relative to the temperature of the third body, and therefore when $20172^{\circ}-17-10$ 
joined in series in the proper sense the combination indicates the temperature difference between the two surfaces. Each multiple couple consists of ro elements joined in series. The elements are made of copper and constantan wires $0.2 \mathrm{~mm}$ in diameter with hard-soldered junctions. The ro elements of each set are bound together into a unit which branches where it enters the vertical receiving tube on the calorimeter or jacket surface. Each of these branches bears 5 junctions; thus, ro junctions are applied to the calorimeter surface and ro to the jacket. Upon the calorimeter each of the Io junctions is so located as to be influenced by one of the ro equal elements of the total surface. Upon the jacket the same is true with the exception that the 2 junctions which properly belong on the top and bottom caps are, for convenience, placed in the receiving tube near the top and bottom. This is considered permissible on account of the uniformity of the jacket temperature, and is done to obviate the difficulties which would attend the soldering of these caps in place without doing injury to junctions upon their surfaces.

It is assumed that the symmetry of the cross section of the calorimeter and the nature of the stirring of the bath obviate the necessity for horizontal integration.

The two complementary sets of ro junctions each enter the pair of adjacent copper tubes which extend through the jacket wall into a metal box which by means of an air space partially insulates the tubes from the bath. The two multiple thermocouples are made and assembled to be as nearly as possible similar, so as to avoid error from lag.

Extending through the ends of the box mentioned above and connected intimately with the two thermocouple tubes is a flat tube just large enough to receive the bulb of a platinum resistance thermometer of the standard calorimetric type inserted from without the bath so as to bring the bulb into close thermal union with the complementary junctions. The air space damps out the small fluctuations of the bath and enables the reference junctions and the thermometer to acquire the same temperature, thus making it possible by means of the thermocouples to make a thermometric transfer from the calorimeter to a second thermometer outside which is thus available as an independent calorimeter thermometer.

The method of experimenting is such that the temperature differences measured by the thermocouples are sufficiently small to per- 


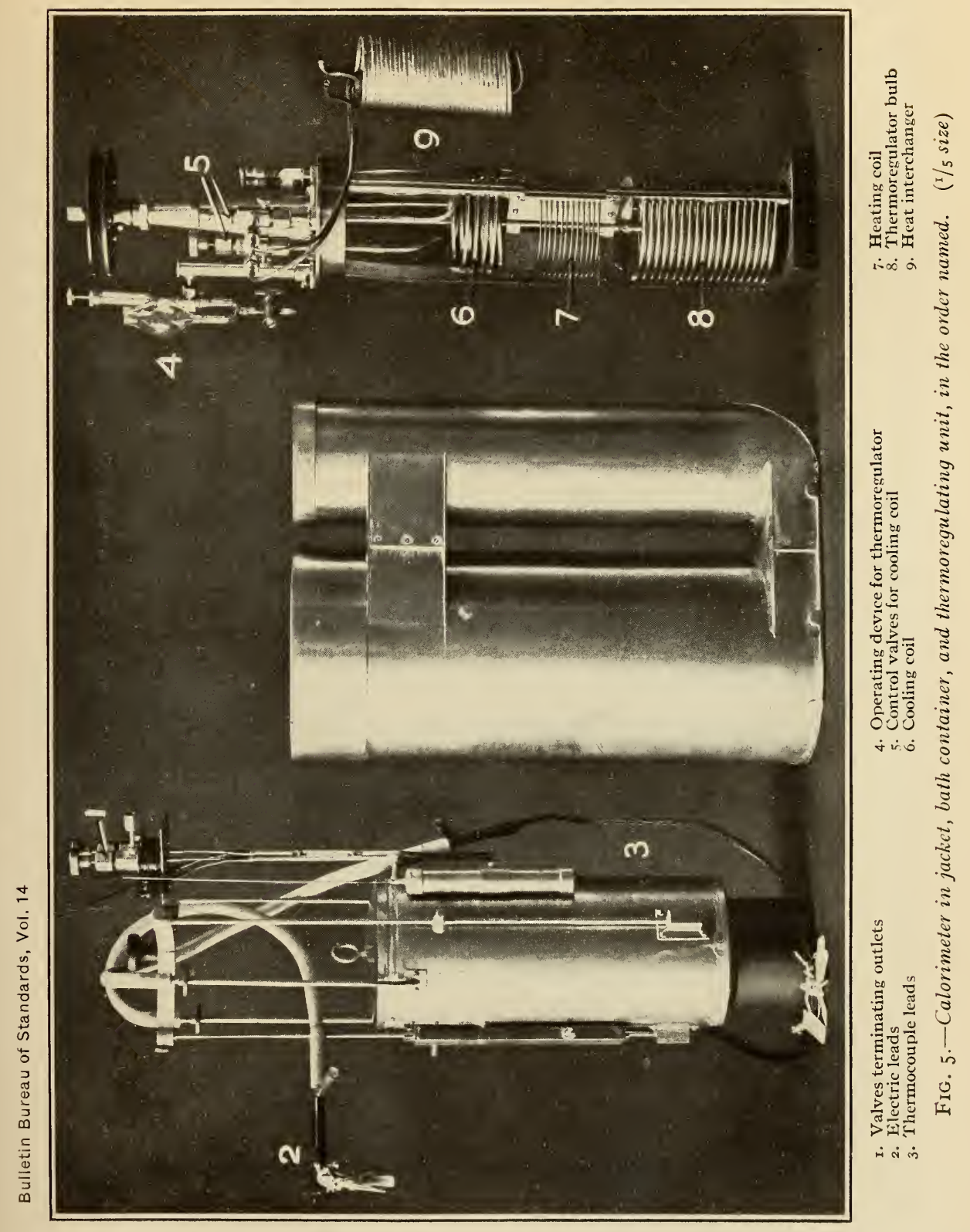




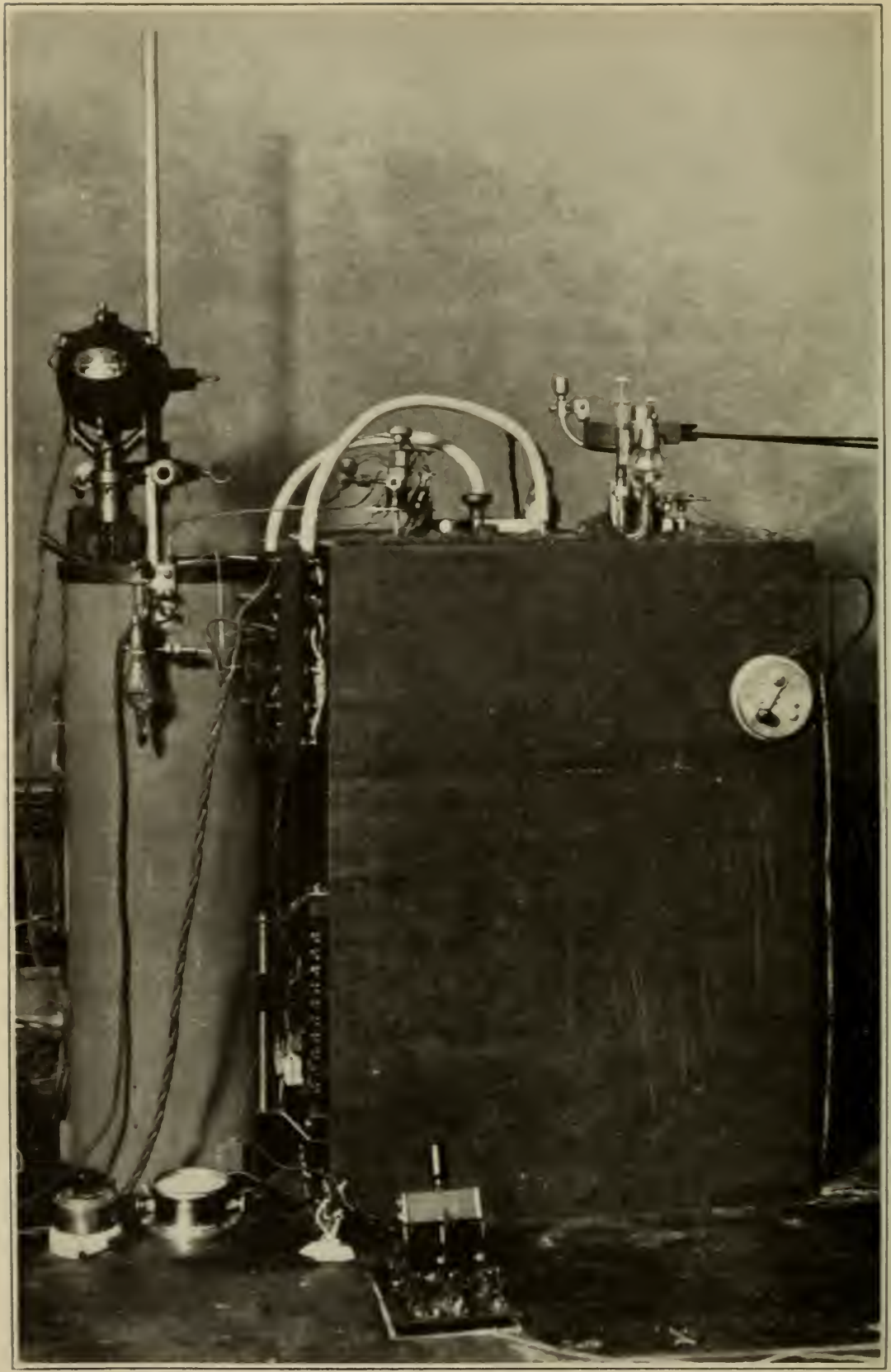

Fig. 0.- Completi culorimeler uith condenser attached. (1 6 size) 
mit their observation to the requisite degree of precision by direct galvanometer deflection. A somewhat complicated arrangement of switch connections is provided to enable the observer with a single galvanometer to shift quickly from any one of the numerous thermoelectric circuits to the Wheatstone bridge thermometric circuit. A thermoelectrically neutral coil of manganin wire with copper leads, wound on a heavy copper spool with close-fitting copper sheath and having a resistance equal to the thermocouple circuit is used to facilitate the resetting of the galvanometer zero. A reversing switch between the galvanometer and couple circuits enables this zero adjustment to be checked. A set of resistances connected through switches in the galvanometer circuit series and parallel give four different critically damped sensitivities on the thermocouples. A sliding multiple-point switch, designed for interchange of the thermocouples leading from the outflow tubes, permits the rapid reading of these couples in succession during evaporation experiments. The contact pieces are all made of copper to avoid thermoelectromotive forces.

\section{THERMOREGULATED BATH}

The function of the stirred bath is to control the jacket temperature. The container for this bath is a brass vessel consisting of two cylindrical vertical tubes connected at bottom and near the top by rectangular ports as shown in Fig. 5. The principal difference from previous models for a similar purpose consists in the separation of the well in which the thermoregulating element is located from the main tube which accommodates the part to be controlled. This prevents local irregularities due to direct conduction from the vicinity of the heating or cooling elements. The diameter of the container is about $4 \mathrm{~cm}$ larger than that of the jacket. A ring fixed inside just below the upper port supports the jacket in position by means of three studs, which lock in place beneath lugs. The cover for the main part is cut into three parts for convenience in assembling, the parts fitting together about the emerging tubes. The liquid used in the range -40 to $+40^{\circ} \mathrm{C}$ is ordinary commercial gasoline.

The thermal control is effected by the unit shown in Fig. 5, which fits the adjacent tube or well in the container. The elements of this unit are a screw propeller driven by shaft and pulley; carbon dioxide refrigerating coil with control valves and heat exchanger; heating coil of Io ohms (diameter, $0.25 \mathrm{~mm}$; B. \& S. 
gage No. 26) asbestos covered constantan sheathed with copper, hermetically sealed to the binding posts; and thermoregulator consisting of tubular coil for bulb and contact-making head.

The lagging is contained in a wooden box shown in Fig. 6, and consists of cork board at bottom and top and granulated cork elsewhere. The minimum thickness of insulating material at any place exceeds $5 \mathrm{~cm}$.

\section{ACCESSORIES}

\section{CONDENSER}

As reservoirs for the material three containers, Fig. 7 , were used. Each is fitted with a tube and valve, which connects to the valve giving access to the calorimeter. The manner of attachment is shown in Fig. 6. The three containers are made of steel, tin coated inside and out. The two smaller ones are used when weighing small samples where the large mass of the larger container would be inconvenient. They have a capacity each of about iso $\mathrm{cm}^{3}$. The capacity of the large container is about $725 \mathrm{~cm}^{3}$.

The containers are interchangeable, and when used in connection with a second thermoregulated bath, as shown in Fig. 5, constitute a condenser and furnish a means of transferring material to or from the calorimeter by distillation.

This thermoregulated bath is contained in a cylindrical Dewar vessel within a metal sheath. A motor-driven stirrer furnishes circulation of the liquid. A carbon dioxide refrigerating coil, an electric-heating coil of Io ohms resistance, and a thermoregulator with relay, etc., constitute the means of thermal control. The fluctuations of temperature in this bath sometimes reached $0.1^{\circ}$, but this regulation was sufficiently good for condenser temperature.

The container is suspended at the axis of the Dewar vessel and is immersed in the circulating liquid.

\section{MANOMETER}

For obtaining an approximate measure of the pressure of the vapor withdrawn in determinations of heat of vaporization a closed manometer, Fig. 8, was used.

The manometer is connected, through its valve, with one of the tubes which lead to the calorimeter, just as the condensers are connected. The frame carrying the manometer tube is mounted upon the flat front of the calorimeter box. The peculiar shape of 
Bulletin Bureau of Standards, Vol. 14

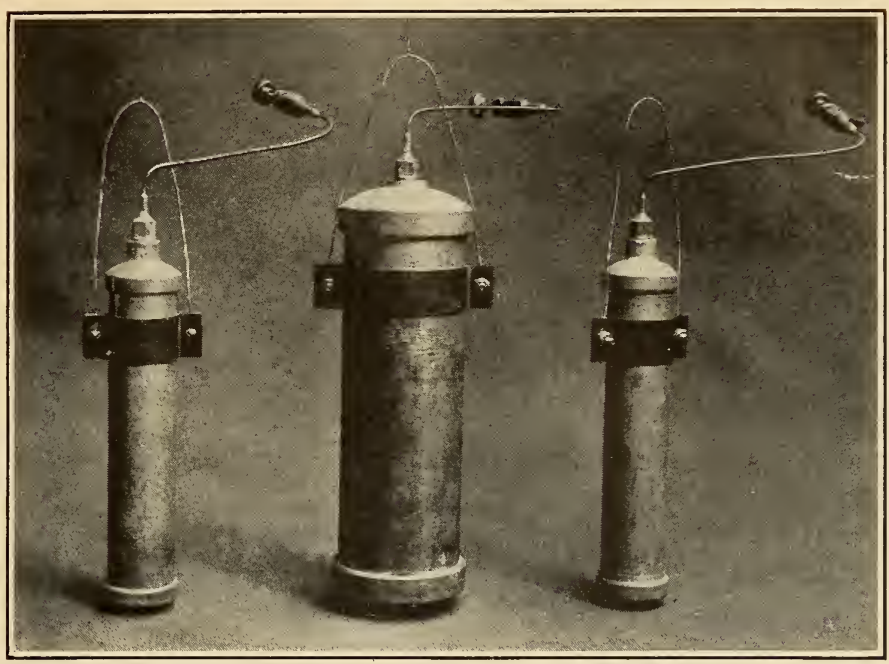

FIG. 7.-Steel containers for ammonia, etc. $\quad(1 / 5$ size $)$

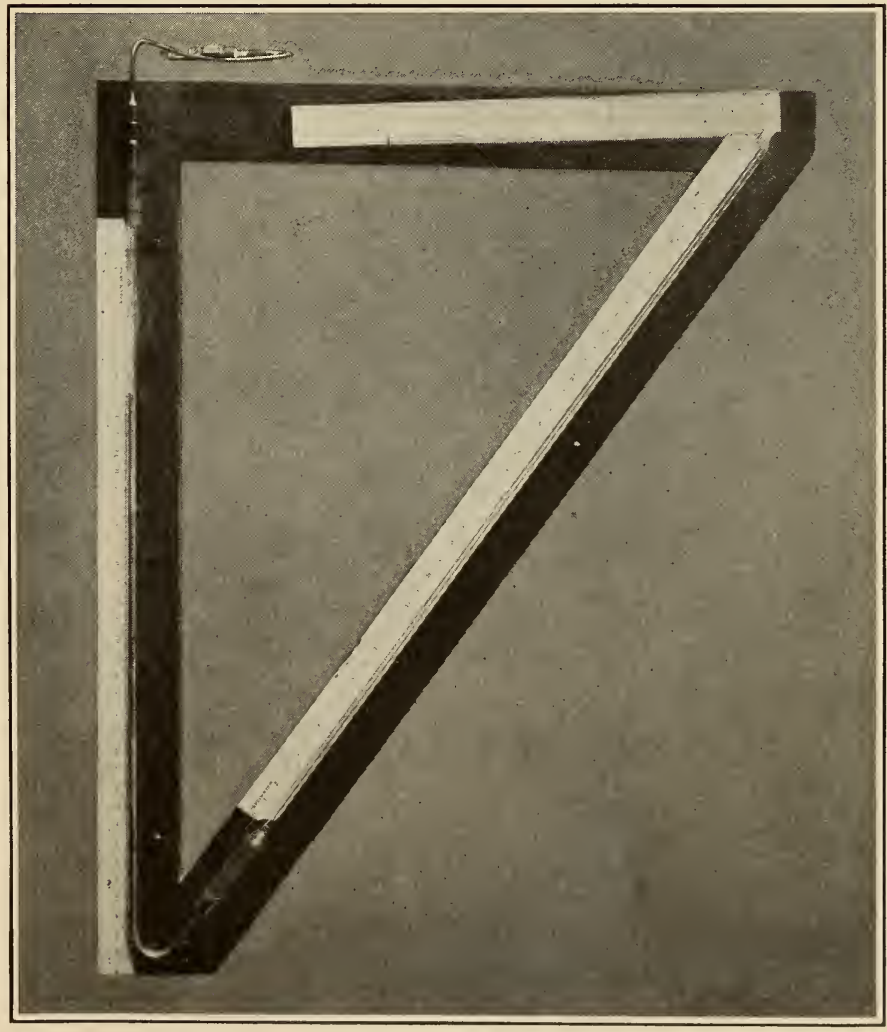

FIg. 8.-Manometer. (ㅈ/6 size) 
the manometer tube results from disposition of the length of tubes used to the available space. The manometer is calibrated at the time of experiments by simultaneous observations of the temperature of the saturated fluid in the calorimeter and the position of the mercury column. As shown, the manometer is adapted for measurement of pressure of saturated vapor only up to the temperature of the room as condensation in the manometer tube would preclude its use for higher calorimeter temperatures.

\section{AUXILIARY APPARATUS}

\section{WHEATSTONE BRIDGE}

The Wheatstone bridge (B. S. No. 748I) used in connection with this calorimeter for observing the platinum thermometer resistances has been described in an earlier publication. ${ }^{8}$

\section{ENERGY-MEASURING APPARATUS}

A Leeds \& Northrup type $\mathrm{K}$ potentiometer was used in conjunction with standard O.I ohm manganin coil and standard IOO:I volt box to measure the current and potential drop in the calorimeter heating coil. The time was recorded chronographically, using the second beats of the Riefler clock by use of the specialrecording quick-throw switch described by Dickinson. ${ }^{9}$

\section{CALIBRATION}

\section{CALIBRATION OF RESISTANCE THERMOMETER}

The ice point resistance $R_{0}$ and fundamental interval $R_{100}-R_{0}$ were determined by direct observations in ice and in steam, and the $\delta$ in the Callendar equation was determined by comparison at $-50^{\circ} \mathrm{C}$ with a standard resistance thermometer (Bureau of Standards C 28) which was calibrated in ice, steam, and sulphur vapor. The scale defined ${ }^{10}$ by the thermometer is therefore the centigrade scale for Heraeus platinum of highest purity according to the equation

$$
\theta=\frac{R_{\theta}-R_{0}}{R_{100}-R_{0}} \mathrm{IOO}+\delta\left(\frac{\theta}{\mathrm{IOO}}-\mathrm{I}\right) \frac{\theta}{\mathrm{IOO}}
$$

when the sulphur boiling point at normal pressure is taken as $444^{\circ} 6$. The value of $\delta$ was found to be r.48.

8 This Bulletin, 11, p. 57r; x9r 4 (Scientific Paper No. 24r).

- This Bulletin, 11, p. 189; 1914 (Scientific Paper No. 230).

10 The departure from the ideal gas scale of the temperature scale so defined, down to $-50^{\circ} \mathrm{C}$, is not more than the limit of accuracy of existing gas thermometer data. 
Subsequent to installing in the calorimeter, and again after reassembling on April IS, 1916, following repairs to the heating coil, the constants depending on the lead resistance were determined, which permit the thermometer to be used as a three-lead compensated type. The values of the ice point resistance $R_{0}$ and fundamental interval $R_{100}-R_{0}$ are given in Table $I$.

TABLE 1

Constants of Calorimeter Thermometer No. 15046

\begin{tabular}{|c|c|c|c|c|}
\hline & \multirow{2}{*}{ Constuats } & \multirow{2}{*}{$\begin{array}{l}\text { Funda- } \\
\text { mental call- } \\
\text { bration as } \\
4-\text { lead } \\
\text { potential } \\
\text { terminal } \\
\text { type }\end{array}$} & \multicolumn{2}{|c|}{$\begin{array}{l}\text { When used as 3-lead } \\
\text { commp e n s a t e d type } \\
\text { using battery lead } \\
\text { designated C }\end{array}$} \\
\hline$i$ & & & $\begin{array}{l}\text { Previous } \\
\text { to Mar. 30, } \\
\qquad 1916\end{array}$ & $\begin{array}{l}\text { After Apr. } \\
18,1916\end{array}$ \\
\hline $\mathbf{R}_{0} \ldots$ & & 24.9688 & 24.9337 & 24. 9325 \\
\hline $\mathbf{R}_{1 \infty}-1$ & & 9.7372 & 9.7431 & 9.7434 \\
\hline
\end{tabular}

The auxiliary resistance thermometer used for check observations by thermocouple transfer was designated "Pt.3, B. S. No. 4725 ," and is one of the standard calorimetric platinum thermometers which have been in use at the Bureau for several years.

\section{RATE OF THERMAL LEARAGE}

The rate of thermal leakage between the calorimeter and jacket was determined throughout the range of temperature in which the calorimeter was used and was checked at various times throughout the progress of the experimental work.

The method of determining this rate was to observe the change in temperature of the calorimeter by means of the resistance thermometer at regular intervals of time while the temperature difference between calorimeter and jacket was kept approximately constant, as indicated by readings of the integrating thermocouples. Determinations were made both with jacket temperature above and below the calorimeter temperature to ascertain whether influences external to the envelope-that is, "lead conduction from the room"-affected the leakage rate. No such effect was detected even at the temperatures furthest from room temperature, showing that the means adopted for intercepting external leakage were adequate. In observing, the readings were continued long enough to insure that a steady state 
was reached. The rate of thermal leakage may be expressed by means of the following equations:

$$
\begin{aligned}
& B=0.146+0.000152 \theta \\
& A=10.4+0.032 \theta
\end{aligned}
$$

$B=$ coefficient of thermal leakage expressed in joules per minute per millimeter deflection of the galvanometer scale as used with integrating thermocouples.

$A=$ coefficient of thermal leakage expressed in joules per minute per degree difference between calorimeter and jacket.

Experiments made to test whether the thermal leakage is correctly determined by the indications of the integrating thermocouples are of two kinds, one of which deals with the leakage occurring when the thermal equilibrium of the calorimeter itself is disturbed but little. In this method the jacket is so manipulated as to induce thermal leakage for a given period, and the actual heat lost or gained by the calorimeter is determined by the change in temperature of the calorimeter observed when in equilibrium before and after this leakage period. The increment so determined was in agreement with that calculated from periodic observations of the integrating thermocouples. The other test consisted of the comparison of the separate determinations of the heat capacity of the calorimeter using first one of the 5 -ohm coils of the heater and then the other. Owing to the location of these coils, one in the upper and the other in the lower half of the calorimeter, the distribution of the surface temperature in the two measurements was different in the two cases. No difference in the measured heat capacity could be detected, showing that for these variations in surface conditions the error in the determination of the thermal leakage by the thermocouples was not appreciable.

\section{THERMOCOUPLE CALIBRATION}

Since the thermocouples were used only for the measurement of small differences of temperature, the necessity for precise calibration was obviated.

The galvanometer sensitivity was determined when in series with a resistance equal to that of the entire thermocouple circuit and used in connection with the known constants for the thermoelectric power of the thermocouple wire. Direct determinations of the combined thermocouple and galvanometer sensitivity agreed with the indirect within the limit of observational error, and the 
indirect method was therefore used for the periodic checking as being the more convenient. The sensitivity when used with the integrating thermocouple corresponded at $0^{\circ}$ to about 0 :or 4 per millimeter deflection. When used to transfer from calorimeter to auxiliary thermometer at $0^{\circ}, 0^{\circ} .0008$ gave $\mathrm{Imm}$ deflection.

\section{HEAT-CAPACITY DETERMINATIONS}

The method of determining the heat capacity of the empty calorimeter or of the calorimeter containing a specimen for obtaining the specific heat is the same.

The first operation is the cooling of the calorimeter to the initial temperature of the first experiment of a series. This is accomplished by use of the cooling device previously described. The jacket is cooled as rapidly as possible by means of the refrigerating coil, and the cooling ring lifted to permit the transfer of the heat from calorimeter to jacket. When the calorimeter temperature is as low as desired the ring is lowered and then the jacket is brought into thermal equilibrium with the calorimeter, using the bath heating coil. Attainment of equilibrium in the calorimeter was ascertained by observing the constancy of temperature indicated by the resistance thermometer when the surfaces of calorimeter and jacket were at the same temperatures as shown by the integrating thermocouples. The empty calorimeter was somewhat slow in reaching equilibrium. Usually 50 minutes were sufficient to reach equilibrium to within 0.001 after a change in temperature. When the calorimeter contained liquid half this time sufficed.

When in equilibrium the initial temperature of the calorimeter is observed by measuring the resistance of the platinum resistance thermometer with the Wheatstone bridge. In addition, or as alternative, the temperature is determined by the outside resistance thermometer in conjunction with the thermocouple reaching from thermometer receptacle to the calorimeter.

The calorimeter heating current is furnished by a large storage battery. This current is set to the proper value in an auxiliary coil, equal in resistance to the calorimeter coil, so connected to a quick throw switch that the current may be instantaneously transferred to the calorimeter coil without any considerable change in value. The potentiometer used to measure the current and potential drop is balanced against the standard cell. 
The heating current is thrown on the calorimeter heater at the beginning of a minute, the instant being recorded automatically on a chronograph. Throughout this period of the experiment, and until equilibrium is again established, the integrating surface thermocouples are observed at equal periods of one minute. The current in the jacket heater is controlled by hand regulation to keep the jacket temperature equal to that of the calorimeter. The thermocouple readings are recorded to the nearest millimeter and the deviations from zero summed at once. It is found to be very easy to make the sum of these deviations for an entire experiment equal to zero, thus eliminating from the computations any correction for thermal leakage, and this is done in practically all heat-capacity experiments. The galvanometer zero is periodically set to the nearest tenth millimeter. Potentiometer readings of current and potential drop in the calorimeter heating coil are taken alternately at equal intervals throughout the period of heating. At the end of a predetermined time interval the current is thrown off and the time again automatically recorded. The jacket is again brought under control of the thermostat at the temperature of the calorimeter and after waiting for the calorimeter to reach equilibrium its final temperature is observed as before. This observation may be taken as the initial temperature of the next experiment and the procedure repeated until completion of the series. The data obtained are:

(a) Initial and final resistance of the thermometer giving temperature change.

(b) Series of values of current and potential drop giving the rate of energy supplied electrically to heat the calorimeter.

(c) Duration of the energy supply.

(d) Record of thermocouple readings of temperature difference between calorimeter and jacket surfaces from which the amount of thermal leakage during the experiment is determined, usually made zero by manipulation.

\section{EXPERIMENTAL RESULTS}

The experimental data corrected for instrumental errors are given, together with the reductions to obtain the heat capacity, in Table 2. The determinations are divided into two series corresponding to the period before and after repairs to the heating coil. 
TABLE 2

\section{Heat Capacity of Calorimeter}

BEFORE REPAIRS

\begin{tabular}{|c|c|c|c|c|c|c|c|c|c|c|c|c|}
\hline Date & $\begin{array}{l}\text { Exp. } \\
\text { No. }\end{array}$ & $\begin{array}{c}\text { Mean } \\
\mathbf{R} \\
\text { Cal. } \\
\text { Therm. }\end{array}$ & $\underset{\theta}{\text { Mean }}$ & $\begin{array}{c}\Delta \theta \\
\text { Cal. } \\
\text { Therm. } \\
15046\end{array}$ & $\begin{array}{c}\Delta \theta \\
\mathrm{Pt}_{3} \\
4725\end{array}$ & $\underset{\Delta \theta}{\text { Mean }}$ & $\begin{array}{l}\text { Heating } \\
\text { coil used }\end{array}$ & $\begin{array}{c}\text { Mean } \\
\text { cur- } \\
\text { rent }\end{array}$ & $\begin{array}{l} \\
\text { Mean } \\
\text { P. D. }\end{array}$ & $\begin{array}{c}\text { Dura- } \\
\text { tion } \\
\text { of } \\
\text { heat- } \\
\text { ing } \\
\text { cur- } \\
\text { reat }\end{array}$ & $\begin{array}{l}\text { En- } \\
\text { ergy }\end{array}$ & $\begin{array}{l}\text { Heat } \\
\text { capac- } \\
\text { ity of } \\
\text { calo- } \\
\text { rime- } \\
\text { ter }\end{array}$ \\
\hline $\begin{array}{l}1916 \\
\text { Feb. } 11\end{array}$ & 1 & $\begin{array}{l}\text { Ohms } \\
29.3499\end{array}$ & $\begin{array}{c}\circ \mathrm{C} \\
+44.96\end{array}$ & $\begin{array}{c}\text { Ohms } \\
10.124\end{array}$ & Ohms & $\begin{array}{c}\text { Ohms } \\
10.124\end{array}$ & 10-ohm.. & $\begin{array}{l}\text { Amps. } \\
1.3059\end{array}$ & $\begin{array}{l}\text { Volts } \\
13.143\end{array}$ & $\begin{array}{l}\text { Secs. } \\
600.00\end{array}$ & $\begin{array}{r}\text { Joules } \\
10298\end{array}$ & $\begin{array}{l}\text { J/deg. } \\
1017.2\end{array}$ \\
\hline \multirow[t]{2}{*}{ Feb. 12} & 1 & 25.7379 & +8.14 & 10.479 & & 10.479 & ...do..... & 1. 3066 & 13. 128 & 600.09 & 10293 & 982.3 \\
\hline & 2 & 26. 7643 & +18.58 & 10. 364 & & 10.364 & ...do... & 1. 3058 & 13. 129 & 600.00 & 10286 & 992.5 \\
\hline Feb. 15 & 1 & 20.4315 & -45.24 & 11.173 & & 11.173 & ...do... & 1.3073 & 13. 105 & 600.00 & 10279 & 920.0 \\
\hline Feb. 16 & 2 & 22.2694 & -26.82 & ....... & 9.860 & 9.860 & Lower 5. & 1. 7566 & 8.840 & 599.95 & 9317 & 944.9 \\
\hline \multirow[t]{5}{*}{ Feb. 17} & 1 & 20.8346 & -41.21 & 9. 995 & 9.993 & 9. 994 & $\ldots$ do..... & 1. 7510 & 8. 804 & 599.95 & 9249 & 925.2 \\
\hline & 2 & 21.8240 & -31.31 & 9. 807 & 9.806 & 9. 807 & ...do.... & 1. 7462 & 8. 784 & 600.09 & 9205 & 938.6 \\
\hline & 3 & 22. 7947 & -21.56 & 9.680 & 9.679 & 9.680 & ...do.... & 1.7452 & 8. 784 & 599.97 & 9197 & 950.2 \\
\hline & 4 & 23. 7508 & -11.82 & 9. 565 & 9. 563 & 9.564 & ...do.... & 1. 7442 & 8.784 & 600.04 & 9193 & 961.0 \\
\hline & 5 & 24.7212 & -2.15 & 10.025 & 10.026 & 10.025 & ...do..... & 1. 7954 & 9.047 & 600.05 & 9747 & 972.2 \\
\hline \multirow[t]{5}{*}{ Feb. 18} & 1 & 26. 0946 & +11.77 & 9.978 & 9.978 & 9.978 & ...do..... & 1. 8034 & 9.090 & 600.03 & 9836 & 985.8 \\
\hline & 2 & 27.0704 & +21.68 & 9. 858 & 9. 854 & 9.856 & ...do..... & 1. 8006 & 9.082 & 600.04 & 9813 & 995.6 \\
\hline & 3 & 28.0569 & +31.73 & 10.252 & 10. 252 & 10.252 & ...do..... & 1.8450 & 9. 312 & 600.00 & 10309 & 1005.5 \\
\hline & 4 & 29.0552 & +41.94 & 10.160 & 10.161 & 10.160 & $\ldots$ do $\ldots .$. & 1.8445 & 9. 316 & 600.08 & 10311 & 1014.9 \\
\hline & 5 & 30.0415 & +52.16 & 10.070 & 10.072 & 10.071 & ...do..... & 1. 8438 & 9.316 & 599.98 & 10306 & 1023.3 \\
\hline \multirow[t]{4}{*}{ Fob. 19} & 1 & 20. 3308 & -46.24 & 11. 231 & & 11.231 & 10-0hm. & 1. 3099 & 13.129 & 599.96 & 10318 & 918.7 \\
\hline & 2 & 21.4152 & -35.40 & 10.441 & & 10.441 & ...do.... & 1. 2726 & 12.762 & 599.96 & 9744 & 933.2 \\
\hline & 3 & 22.4747 & -24.78 & 10.805 & & 10.805 & ...do..... & 1.3036 & 13.079 & 599.97 & 10230 & 946.7 \\
\hline & 4 & 23. 5417 & -14.05 & 10.658 & & 10.658 & ...do..... & 1. 3028 & 13.077 & 600.01 & 10222 & 959.1 \\
\hline \multirow[t]{5}{*}{ Feb. 21} & 1 & 24.4684 & -4.71 & 10.711 & & 10.711 & ...do..... & 1. 3125 & 13.180 & 599.96 & 10379 & 969.0 \\
\hline & 2 & 25.5193 & +5.93 & 10.550 & & 10.550 & ...do..... & 1. 3098 & 13. 159 & 600.08 & 10343 & 980.4 \\
\hline & 3 & 26.5520 & +16.41 & 10.408 & & 10.408 & ...do..... & 1. 3076 & 13.142 & 600.00 & 10310 & 990.6 \\
\hline & 4 & 27.5687 & +26.75 & 10.287 & & 10.287 & ...do..... & 1. 3062 & 13.133 & 600.03 & 10293 & 1000.6 \\
\hline & 5 & 28.5706 & +36.99 & 10.170 & & 10.170 & ...do..... & 1. 3045 & 13. 124 & 600.04 & 10273 & 1010.1 \\
\hline \multirow[t]{2}{*}{ Mar. 8} & 1 & 27.4352 & +25.39 & 8.890 & 8. 885 & 8.888 & Upper 5. & 1. 7141 & 8.630 & 600.12 & 8878 & 998.8 \\
\hline & 2 & 28. 3052 & +34.27 & & 8. 849 & 8. 849 & ...do..... & 1.7138 & 8. 632 & 602.16 & 8908 & 1006.7 \\
\hline
\end{tabular}

After emptying first filling

\begin{tabular}{l|l|l|l|l|l|l|l|l|l|l|l|l}
\hline Mar. 17 & 1 & 27.1856 & +22.85 & $\ldots \ldots .$. & 9.827 & 9.827 & $10-0 h m .$. & 1.2740 & 12.808 & 600.00 & 9790 & 996.2 \\
\hline
\end{tabular}

After emptying second filling

\begin{tabular}{|c|c|c|c|c|c|c|c|c|c|c|c|c|}
\hline \multirow[t]{3}{*}{ Mar. 27} & 1 & 20.4692 & -44.86 & & 10.668 & 10.668 & 10-ohm. & 1. 2792 & 12. 820 & 599.83 & 9837 & 922.1 \\
\hline & 2 & 21. 5276 & -34.28 & & 10.492 & 10.492 & $\ldots$ do.... & 1. 2772 & 12. 807 & 600.04 & 9815 & 935.5 \\
\hline & 3 & 22. 5658 & -23.86 & & 10.332 & 10.332 & ..do... & 1. 2754 & 12. 796 & 600.24 & 9796 & 948.1 \\
\hline \multirow[t]{5}{*}{ Mar. 28} & 1 & 23. 2541 & -16.95 & 10.178 & 10. 175 & 10. 177 & ..do... & 1. 2709 & 12. 756 & 600.05 & 9728 & 955.9 \\
\hline & 2 & 24. 2573 & -6.83 & 10.045 & 10.046 & 10.045 & ..do... & 1. 2699 & 12. 752 & 599.95 & 9716 & 967.2 \\
\hline & 3 & 25. 2453 & +3.15 & 9.927 & 9.923 & 9.925 & . do... & 1.2686 & 12. 752 & 599.93 & 9705 & 977.8 \\
\hline & 4 & 26. 2189 & +13.02 & 9. 814 & 9. 816 & 9. 815 & ..do.. & 1. 2678 & 12. 740 & 599.97 & 9691 & 987.3 \\
\hline & 5 & 27. 1789 & +22.78 & 9.708 & 9.711 & 9. 709 & ...do... & 1. 2671 & 12.738 & 600.01 & 9684 & 997.4 \\
\hline
\end{tabular}


TABLE 2-Continued

Heat Capacity of Calorimeter-Continued

AFTER REPAIRS

\begin{tabular}{|c|c|c|c|c|c|c|c|c|c|c|c|c|}
\hline Date & $\begin{array}{l}\text { Exp. } \\
\text { No. }\end{array}$ & $\begin{array}{c}\text { Mean } \\
\mathbf{R} \\
\text { Cal. } \\
\text { Therm. }\end{array}$ & $\underset{\theta}{\text { Mean }}$ & $\begin{array}{c}\Delta \theta \\
\text { Cal. } \\
\text { Therm. } \\
15046\end{array}$ & $\begin{array}{c}\stackrel{\Delta \theta}{\mathbf{P} \mathrm{t}_{3}} \\
4725\end{array}$ & $\underset{\Delta \theta}{\text { Mean }}$ & $\begin{array}{l}\text { Heating } \\
\text { coil used }\end{array}$ & $\begin{array}{c}\text { Mean } \\
\text { cur- } \\
\text { rent }\end{array}$ & $\begin{array}{l}\text { Mean } \\
\text { P. D. }\end{array}$ & $\begin{array}{c}\text { Dura- } \\
\text { tion } \\
\text { of } \\
\text { heat- } \\
\text { ing } \\
\text { cur- } \\
\text { rent }\end{array}$ & $\begin{array}{l}\text { En- } \\
\text { ergy }\end{array}$ & $\begin{array}{l}\text { Heat } \\
\text { capac- } \\
\text { ity of } \\
\text { calo- } \\
\text { rime- } \\
\text { ter }\end{array}$ \\
\hline \multirow[t]{2}{*}{$\begin{array}{c}1916 \\
\text { Apr. } 19\end{array}$} & 1 & $\begin{array}{l}\text { Ohms } \\
20.4324\end{array}$ & $\begin{array}{c}\circ \mathrm{C} \\
-45.22\end{array}$ & $\begin{array}{c}\text { Ohms } \\
11.378\end{array}$ & $\begin{array}{c}\text { Ohms } \\
11.377\end{array}$ & $\begin{array}{c}\text { Ohms } \\
11.378\end{array}$ & 10-ohm. & $\begin{array}{l}\text { Amps. } \\
1.3198\end{array}$ & $\begin{array}{l}\text { Volts } \\
13.197\end{array}$ & $\begin{array}{l}\text { Secs. } \\
599.95\end{array}$ & \begin{tabular}{|} 
Joules \\
10449
\end{tabular} & $\begin{array}{l}\mathrm{J} / \text { deg. } \\
918.4\end{array}$ \\
\hline & 2 & 21.5619 & -33.93 & 11.209 & 11. 207 & 11.208 & ...do..... & 1.3196 & 13. 205 & 600.27 & 10460 & 933.2 \\
\hline \multirow[t]{2}{*}{ Apr. 24} & 1 & 22.1336 & -28.20 & 11. 301 & 11. 292 & 11. 296 & ...do.... & 1. 3301 & 13.312 & 600.05 & 10624 & 940.5 \\
\hline & 2 & 23. 2514 & -16.96 & 11. 161 & 11. 159 & 11.160 & ...do..... & 1. 3310 & 13.333 & 600.14 & 10650 & 954.3 \\
\hline \multirow[t]{4}{*}{ Apr. 25} & 1 & 23. 8154 & -11.27 & 11.000 & 11.001 & 11.000 & ...do..... & 1.3258 & 13. 285 & 599.95 & 10567 & 960.6 \\
\hline & 2 & 24.8980 & -.35 & 10.862 & 10.861 & 10.862 & ...do..... & 1. 3248 & 13. 282 & 599.95 & 10557 & 971.9 \\
\hline & 3 & 25.9636 & +10.44 & 10.722 & 10. 717 & 10.720 & ...do...... & 1.3233 & 13.274 & 600.00 & 10539 & 983.1 \\
\hline & 4 & 27.0126 & +21.10 & 10.596 & 10.600 & 10.598 & ...do...... & 1.3222 & 13.270 & 600.01 & 10528 & 993.4 \\
\hline \multirow[t]{3}{*}{ Apr. 26} & 1 & 27.5239 & +26.31 & 10.542 & 10.542 & 10.542 & ...do..... & 1.3218 & 13.270 & 599.99 & 10524 & 998.3 \\
\hline & 2 & 28.5499 & +36.79 & 10.421 & 10.422 & 10.421 & $\ldots$....... & 1. 3202 & 13.260 & 600.06 & 10505 & 1008.1 \\
\hline & 3 & 29.5618 & +47.14 & 10.301 & 10.300 & 10. 301 & ...do..... & 1.3185 & 13.249 & 600.00 & 10481 & 1017.5 \\
\hline
\end{tabular}

After emptying

\begin{tabular}{|c|c|c|c|c|c|c|c|c|c|c|c|c|c|}
\hline \multirow[t]{4}{*}{ July } & 5 & 1 & 20.7806 & -41.80 & 11.115 & 11.112 & 11.114 & 10-0hm. & 1. 3076 & 13. 081 & 600.00 & 10263 & 923.4 \\
\hline & & 2 & 21.8821 & -30.72 & 10.933 & 10.930 & 10.932 & ...do.... & 1. 3065 & 13.079 & 599.95 & 10252 & 937.8 \\
\hline & & 3 & 22.9629 & -19.86 & 10.768 & 10.764 & 10.766 & ...do & 1. 3053 & 13. 075 & 599.86 & 10238 & 950.9 \\
\hline & & 4 & 24. 0244 & -9.17 & 10.615 & 10.616 & 10.615 & ...do.. & 1. 3042 & 13.071 & 600.03 & 10229 & 963.6 \\
\hline \multirow[t]{3}{*}{ July } & 6 & 1 & 24.5432 & -3.94 & 10.392 & 10.389 & 10. 391 & ...do. & 1. 2930 & 12.963 & 600.02 & 10057 & 967.9 \\
\hline & & 2 & 25. 5644 & +6.39 & 10.259 & 10.256 & 10.258 & ...do.. & 1. 2927 & 12.957 & 600.01 & 10050 & 979.7 \\
\hline & & 3 & 26. 5699 & +16.60 & 10. 149 & 10.147 & 10.148 & ...do. & 1. 2911 & 12.956 & 600.03 & 10037 & 989.1 \\
\hline
\end{tabular}

The reductions are made according to the formula

$$
N=\frac{I E t^{\prime}+B t_{2} h}{K \Delta R}
$$

The notation used:

$N=$ heat capacity of the calorimeter at temperature $\theta$, in joules per degree.

$I=$ current, in amperes ${ }^{11}$ (mean value).

$E=$ potential drop, in volts ${ }^{12}$ (mean value).

11 The ampere, which is here used only as an intermediary unit, is determined by the relation $I=\frac{E}{R}$ where $I=$ number of amperes.

${ }^{12}$ Where numerical values are given the joule used in this paper is determined by the relation $\frac{Q}{t}=\frac{E^{2}}{R}$ where $Q$ is the number of joules transformed into heat in a given electric circuit in $\ell$ seconds, $E$ the number of volts potential drop, and $R$ the number of ohms resistance; taking $\mathrm{I}$ volt $=\frac{T}{1.01830} \times \mathrm{emf}$ of mean Weston normal cell at $20^{\circ} \mathrm{C}$, and $\mathrm{I} \mathrm{ohm}=$ resistance at $0^{\circ} \mathrm{C}$ of $106.300 \mathrm{~cm}$ of uniform mercury column $x 4.452 \mathrm{I} \mathrm{g}$ in mass. The difference between the international joule, realized thus, and the absolute joule is, accordin to present evidence, perhaps I part in 3000 . (Bureau of Standards Circular No. 6o, Ist ed., p. 56; I9I6.) 
$t=$ time.

$t_{1}=$ time at instant of starting the heating current when calorimeter is at $\theta_{1}, t_{1}$ is usually taken as zero.

$t^{\prime}=$ time of stopping the heating current, or duration of heating current when $t_{1}=0$.

$t_{2}=$ time when final equilibrium temperature $\theta_{2}$ is observed, or duration of entire experiment when $t_{1}=0$.

$h=$ mean thermocouple indication of the galvanometer scale during entire experiment, in millimeters.

$B=$ coefficient of thermal leakage in joules per minute per millimeter galvanometer deflection.

$R_{1}=$ initial resistance of thermometer, in ohms.

$R_{2}=$ final resistance of thermometer, in ohms.

$\Delta R=$ change in thermometer resistance during experiment, in ohms.

$K=$ difference factor for resistance thermometer, i. e., $\frac{\Delta \theta}{\Delta R}$

In the determinations recorded in Table 2 the mean thermocouple indication, $h$, during the entire experiment was in each case made zero and is therefore omitted. The duration of each experiment was about 60 minutes.

TABLE 3

Journal of Experiments with Calorimeter, Showing the Distribution of Heat-Capacity Determinations

\begin{tabular}{|c|c|c|}
\hline $\begin{array}{l}\text { Heat capacity of empty } \\
\text { calorimeter }\end{array}$ & $\begin{array}{l}\text { Specific heat of liquid } \\
\text { ammonia }\end{array}$ & $\begin{array}{c}\text { Latent heat of vaporization of } \\
\text { ammonia }\end{array}$ \\
\hline $\begin{array}{l}\text { Feb. } 11 \text { to Mar. } 8,1916 . . \\
\text { Mar. } 17 \text { to Msr. } 26,1916 . \\
\text { Mar. } 31,1916 . \ldots \ldots \ldots \ldots .\end{array}$ & $\begin{array}{l}\text { Mar. } 13 \text { to Mar. 16, } 1916 . \\
\text { Mar. } 27 \text { to Mar. 28, } 1916 . \\
\ldots \ldots \ldots \ldots \ldots \ldots \ldots \ldots \ldots \ldots . \ldots \ldots \ldots \ldots\end{array}$ & \\
\hline \multicolumn{3}{|c|}{ Heating coil falled; repairs made } \\
\hline $\begin{array}{l}\text { Apr. } 19 \text { to Apr. } 26,1916 \ldots \\
\text { July } 5 \text { to July } 6,1916 \ldots \ldots\end{array}$ & & Apr. 26 to July 5, 1916. \\
\hline
\end{tabular}

By noting the dates of the several experiments it is seen that several groups have been made. These groups bear a relation to the various fillings of the calorimeter for determinations of specific heat and latent heat of vaporization.

In the heat-capacity determinations experiments were made using each 5 -ohm section of the heating coil alone, and also using both together.

In regard to the precision of the measurements of the heat capacity of the calorimeter, except for the actual change which 


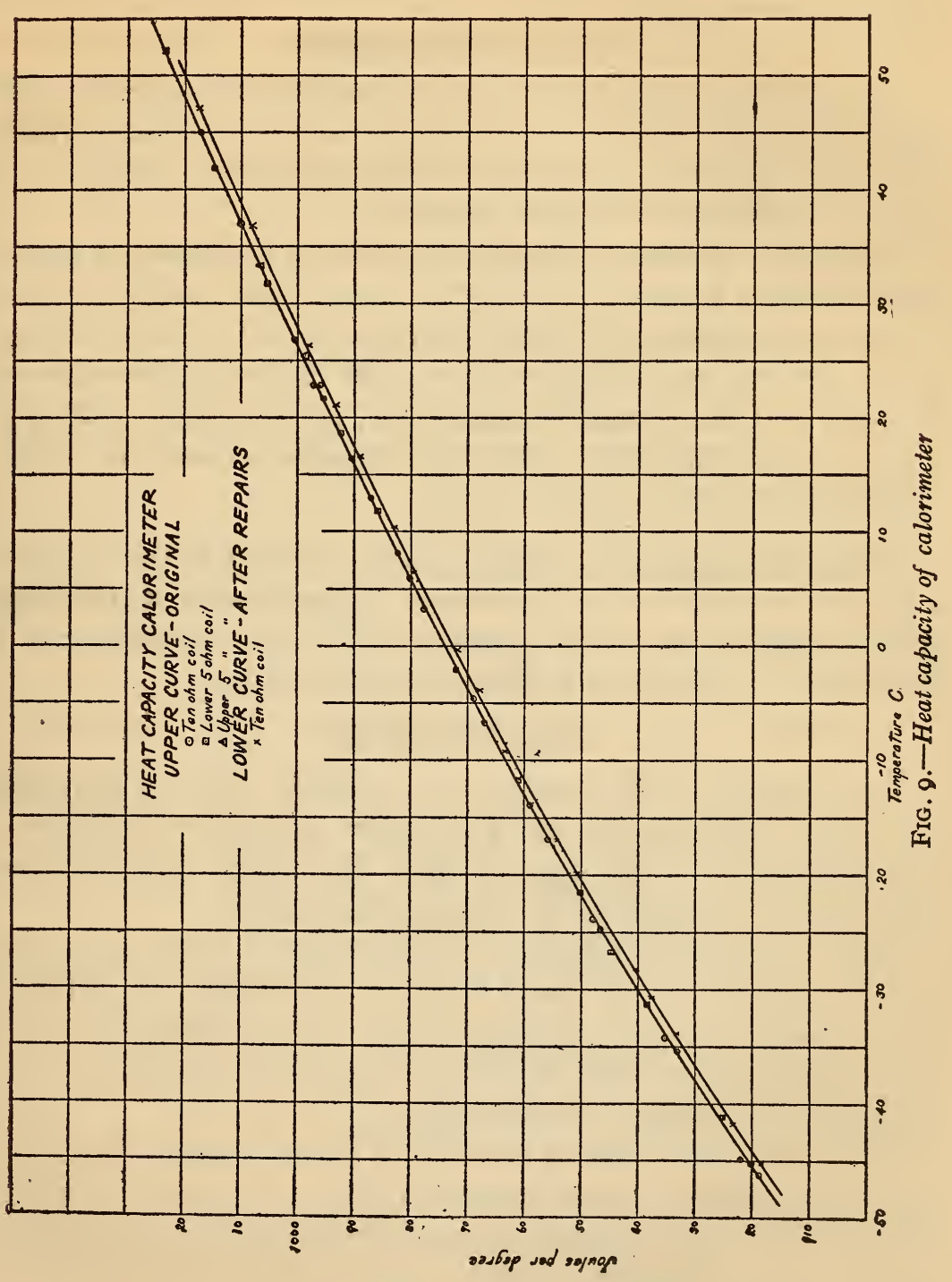


resulted from the repairs, the maximum deviation from the mean of any single measurement was not more than I part per Iooo, and the average deviation from the mean was not more than 3 parts in ro ooo. The results of all the determinations are shown graphically in Fig. 9.

\section{APPLICATIONS}

The calorimeter has been used to determine the specific heat of liquid ammonia at saturation pressure and at constant pressure, the latent heat of vaporization of liquid ammonia, and the latent heat of compression of liquid ammonia.

The results of these determinations will be presented in separate papers in this Bulletin. It may be stated here that the precision of the measurements of specific heats and heat of vaporization is of the order of one-tenth per cent, while the heat of compression, which is of a much smaller magnitude, is determined with a precision of 3 to 5 per cent. The determinations cover the range of temperature from -40 to $+40^{\circ} \mathrm{C}$.

The author is especially indebted for assistance in the design and construction to Dr. H. C. Dickinson; for assistance in the experimental work to M. S. Van Dusen, and for the excellence of the mechanical execution to F. Knoop, mechanician.

\section{SUMMARY}

The principle of the unstirred or "aneroid" type of calorimeter has been embodied in an instrument especially designed for determinations of the specific heat and latent heat of several substances in general use as refrigerating media.

Heat developed electrically in a coil located in the central axis of the cylindrical shell comprising the calorimeter is distributed by conduction to the calorimeter and contents whose initial and final temperatures when in thermal equilibrium are measured by a platinum resistance thermometer.

Heat from other sources is excluded by enveloping the calorimeter with a metal jacket separated from it by an air space and keeping this jacket during measurements at the same temperature as the calorimeter surface, using multiple thermocouples to indicate this equality.

The calorimeter is adapted for use between -50 and $+50^{\circ} \mathrm{C}$ and for pressures up to 70 atmospheres in experiments where the measured heat added is used either to change the temperature of the contents or to evaporate a portion of the contents withdrawn as superheated vapor, in the first case the specific heat and in the 
second the latent heat of vaporization being obtained when proper corrections are made. Such experiments are described in separate papers, this paper being devoted to the description of the instrument and its calibration.

Several features to which special attention has been given are:

I. Refinements to reduce errors in the evaluation of thermal leakage. These refinements include the following details:

(a) Location of the heater in the central axis of the calorimeter so that abrupt thermal irregularities produced by the heat developed therein may be subdued before affecting the surface.

(b) Distribution of metal connections between calorimeter and jacket in such a way that the lead conduction is unaffected by inequalities in the surface temperature of the calorimeter.

(c) By means of superficial copper sheaths protection of the calorimeter surface from abrupt variations in temperature such as may occur within during calorimetric measurements.

(d) Method of indicating relative mean surface temperatures of calorimeter and jacket by means of multiple integrating thermocouples, which permits the evaluation of and usually the annulment of the thermal leakage.

2. Provision by means of a system of radial metal vanes for the distribution of heat throughout the contents.

3. Provision for insuring the dryness of vapor withdrawn by means of baffle plate system.

4. Installation in the calorimeter of a strain-free type of platinum resistance thermometer selected to give requisite accuracy.

5. Device for rapid cooling of the calorimeter, consisting of a copper ring which can be moved within the jacket so as to thermally short-circuit the insulating air space and permit the escape of heat to the cooled jacket.

6. Thermoregulated bath for keeping the temperature of the isothermal envelope or jacket always under control of the observer in order to avoid any unmeasured heat increments by thermal leakage.

Many other details are described which have a bearing on the convenience or accuracy in the use of the instrument.

The method of manipulation in making measurements of heat capacity is described, and the results given of an extended series of observations in the temperature range from -50 to $+50^{\circ} \mathrm{C}$ to determine the heat capacity of the empty calorimeter.

WASHINGTON, February Io, I9r 7. 